\title{
Strategic planning for saving the lives of mothers, newborns and children and preventing stillbirths in KwaZulu-Natal province South Africa: modelling using the Lives Saved Tool (LiST)
}

Shelley-Ann McGee', Lumbwe Chola', Aviva Tugendhaft', Victoria Mubaiwa², Neil Moran²,3, Neil McKerrow ${ }^{2,4}$, Leonard Kamugisha ${ }^{5}$ and Karen Hofman ${ }^{1 *}$

\begin{abstract}
Background: KwaZulu-Natal province in South Africa has the largest population of children under the age of five and experiences the highest number of child births per annum in the country. Its population has also been ravaged by the dual epidemics of HIV and TB and it has struggled to meet targets for maternal and child mortality. In South Africa's federal system, provinces have decision-making power on the prioritization and allocation of resources within their jurisdiction. As part of strategic planning for 2015-2019, KwaZulu-Natal provincial authorities requested an assessment of current mortality levels in the province and identification and costing of priority interventions for saving additional maternal, newborn and child lives, as well as preventing stillbirths in the province.

Methods: The Lives Saved Tool (LiST) was used to determine the set of interventions, which could save the most additional maternal and child lives and prevent stillbirths from 2015-2019, and the costs of these. The impact of family planning was assessed using two scenarios by increasing baseline coverage of modern contraception by 0.5 percentage points or 1 percentage point per annum.

Results: A total of 7,043 additional child and 297 additional maternal lives could be saved, and 2,000 stillbirths could be prevented over five years. Seventeen interventions account for $75 \%$ of additional lives saved. Increasing family planning contributes to a further reduction of up to 137 maternal and 3,168 child deaths. The set of priority interventions scaled up to achievable levels, with no increase in contraception would require an additional US\$91 million over five years or US\$1.72 per capita population per year. By increasing contraceptive prevalence by one percentage point per year, overall costs to scale up to achievable coverage package, decrease by US\$24 million over five years.
\end{abstract}

Conclusion: Focused attention on a set of key interventions could have a significant impact on averting stillbirths and maternal and neonatal mortality in KwaZulu-Natal. Concerted effort to prioritize family planning will save more lives overall and has the potential to decrease costs in other areas of maternal and child care.

Keywords: Mortality, Contraception, Maternal health, Stillbirths, Child health, Cost analysis, South Africa

\footnotetext{
* Correspondence: karen.hofman@wits.ac.za

${ }^{1}$ Priority Cost-Effective Lessons for System Strengthening South Africa (PRICELESS SA), Medical Research Council/Wits Rural Public Health and Health Transitions Research Unit (Agincourt), Wits School of Public Health, Faculty of Health Sciences, University of the Witwatersrand, Wits Education Campus, 27 St Andrews Road, Parktown 2193, Johannesburg, South Africa Full list of author information is available at the end of the article
} 


\section{Background}

South Africa has experienced an acceleration in the reduction of child mortality since 2006 [1] and a reversal of an increasing trend in maternal mortality ratios [2]. By 2013, national estimates put under-5 mortality rate at 41 per 1,000 live births, infant mortality rate at 29 per 1,000 live births and the maternal mortality ratio at 197 per 100,000 live births [2]. Despite this progress, South Africa has not reached the Millennium Development Goals (MDGs) for maternal and child mortality in 2015, which are 20 per 1,000 live births, 18 per 1,000 live births and 38 per 100,000 live births for under-5, infant and maternal mortality respectively [3]. In 2013, the country sought to identify key interventions that would be most effective in saving additional lives of mothers, newborns and children, in the 2 years leading up to the MDG deadline [3]. The aim was to contribute to a national strategy to reduce maternal and child mortality by 2015 and ensure progress towards the sustainable development goals. In line with this national agenda, the KwaZulu-Natal (KZN) provincial health department sought to localize the analysis, to identify context specific interventions that could save the lives of mothers and children in KZN.

The federal provincial structures in South Africa place provinces in control of resource allocations within their own jurisdictions. The National Health Act requires provincial Departments of Health to develop their own strategic plans, which must conform with national health policy [4]. This provides the provinces with the structure to implement their own priorities, responsive to the needs of their particular populations. KZN is the epicenter of the HIV/AIDS epidemic in the country, with an estimated HIV prevalence of $16.9 \%$, versus the national estimate of $12.2 \%$ [5].

In 2014, the KwaZulu-Natal Department of Health, Maternal and Child and Women's Health Unit began its strategic planning cycle for 2015-2019. The National Treasury requires that provinces and departments develop strategic plans and annual performance plans that are led by the South African Presidency [6]. The Treasury framework recommends that the costs of initiatives be linked with results to ensure value for money.

As part of the planning process, the $\mathrm{KZN}$ province sought to identify the cost and impact of scaling up essential interventions that could save additional lives of mothers, newborns and children, as well as prevent stillbirths in the province. With appreciation for the national set of priorities which had been determined in the national MDG analysis [3], the $\mathrm{KZN}$ provincial authorities wanted to identify a priority set of interventions specific to their own demographics and burden of disease for 2015-2019.
A process was initiated to evaluate the current situation in the province, better understand the challenges faced in terms of maternal and child mortality and use an available policy development software tool to model the potential impact on maternal and child mortality that could be achieved over the strategic five year period.

This analysis aimed to identify and cost a set of interventions to be prioritized and scaled up by 2019 to reduce maternal, newborn and child deaths and prevent stillbirths in the province.

\section{Methods \\ Study area}

KwaZulu-Natal (KZN) province is the second most populous province in South Africa, and has the largest population of children under five years old with 1.3 million in 2014 [7] or $22 \%$ of the children in the country. The province also has the largest population dependent on the public health sector for services [8]. KZN has been the most severely impacted by the country's HIV/AIDS and tuberculosis epidemics. It is the province with the highest HIV prevalence in antenatal clients, at $37.4 \%$ [9] and the highest incidence of tuberculosis in the general population, at 971 per 100,000 population in 2012 [10].

Since 2010, however, maternal and child health indicators have been improving. Maternal mortality in healthcare facilities in the province has decreased from a peak of 209 per 100,000 live births in 2010, down to 160 per 100,000 live births in 2012 [11, 12]. The figures are likely an underestimate, however, as recording and reporting on maternal deaths outside of healthcare facilities remains a challenge in the country [13]. Under five deaths in the province have decreased by about $46 \%$ from 13,000 in 2007 to 7,000 in 2011 [14]. Having achieved considerable success in coverage of prevention of mother to child transmission of HIV (PMTCT) as well as improvement in access to antiretroviral treatment, the province is in a position to consider the potential impacts of other key interventions for saving the lives of mothers and children.

\section{Modelling software}

The analysis was undertaken using the Lives Saved Tool (LiST) within the Spectrum software (Futures Institute, now Avenir Health, United States of America), which was developed to support decision making in the health sector $[15,16]$. The Spectrum program consists of several modules which interact with one another to address a variety of issues in demography and population health. The demographic projection model (DemProj) forms the basis for any Spectrum projection and requires inputs 
on various determinants of population dynamics, including fertility rates, mortality rates and population age distribution. The modelling for maternal and child health impacts is done in the LiST, while the Family Planning (FamPlan) Module examines the impacts of changing contraceptive use prevalence and methods mix. FamPlan requires inputs on total fertility, and contraceptive prevalence, as well as the proximate determinants of fertility including the proportion of women of reproductive age married or in a sexual union, duration of postpartum insusceptibility, abortion rates and degree of pathological sterility in the population [16]. The analysis was conducted using Spectrum version 5.06.

The functionality of LiST has been described in detail in previous publications [17-19]. LiST is a linear mathematical model which describes fixed relationships between inputs, which are primarily levels of coverage for a set of interventions, and outputs in terms of changes in population level risk factors and causes of mortality in children, neonates, pregnant women and stillbirths [18]. LiST is capable of analyzing the impact of the scale up of multiple interventions, which may be effective in reducing risk and mortality from several causes. For example, one particular scenario modelled can calculate the impact of a package of interventions as they are scaled up from a baseline coverage level to forecast the impact of various projected levels of coverage over time.

LiST preloads national-level data for health status, mortality rates, and coverage of approximately 70 interventions, and their effectiveness in relation to specific causes of death in mothers, neonates and children under 5 years of age for a national level analysis $[17,20]$. The Spectrum software allows for sub-national analyses to be constructed using a country-based model. In order to complete the province-specific analysis, a subnational population scenario was developed within a national level baseline model [3]. This involved collection of province-specific information on population numbers and growth rate, total fertility rates, contraceptive prevalence rate and HIV prevalence information for KZN province [5, 7, 9].

The LiST default settings do not carry all possible interventions, thus several additional interventions were included in the modelling, in response to existing policies and burden of disease. Given the significant burden of HIV and TB in the province, treatment of childhood tuberculosis [21], treatment of tuberculosis in pregnant women [22], as well as early detection and treatment of HIV in pregnant women were included. In response to the Free State province's success in reducing maternal mortality with improved interfacility transport for obstetric emergencies, this was also included as a potentially impactful intervention [23]. In children between 1 and 4 years old, non-natural causes are responsible for $17.4 \%$ of total deaths, with external sources of accidental injury as the source of $70 \%$ of these non-natural deaths [24]. Thus treatment of childhood injuries was also included as an intervention to save child lives between the ages of 1 and 59 months [25].

These interventions were assigned to the causes of death which they could potentially affect. Intervention effectiveness was drawn from the literature and expert input from a national Millennium Development Goal Countdown analysis in LiST which was undertaken for South Africa in 2013 [3, 21, 23, 26]. Details of the effect sizes and affected fractions which were applied to the model are given in Additional file 1: Sheet 1.

Adequately modelling the provincial-level impact of different interventions required the following:

- A baseline assessment of demographic information, epidemiological detail (particularly on HIV and tuberculosis), rates and causes of maternal and child mortality and stillbirths and several other indicators contributing to the LiST Tool.

- Estimation of current (baseline) coverage of the LiST set of interventions.

- Extrapolating the impacts of different scenarios of coverage from baseline in 2014 to the end of the strategic period in 2019.

- Estimating the costs of the scenario to assist in budgeting and planning.

\section{Baseline analysis}

Data to populate the Spectrum Suite were drawn from a number of sources available on HIV, maternal and child health indicators, under- 5 and maternal deaths and stillbirths in the province, as well as estimates of the coverage levels of interventions in LiST but not routinely monitored or reported in South Africa.

Burden of disease estimates for 2011 for maternal, neonatal and child deaths were derived from the $\mathrm{Na}$ tional Committee on Confidential Enquiries into Maternal Deaths (NCCEMD) data, and vital registration data $[14,27]$. The causes of maternal, neonatal and under-5 deaths were adapted in consultation with the provincial clinical team to fit the causal categories provided by LiST. Mortality rates were determined for 2011 or the closest year.

Many of the interventions in LiST are not tracked on a consistent basis within the health monitoring systems. The baseline coverage for LiST indicators was determined using national data from the District Health Information System [28] where possible. Where estimates were not available from standard database sets, the provincial clinical and management team was asked to estimate the coverage for particular interventions, based on their experience and knowledge of the health services in the province. 
This team consisted of the head of the maternal and child health programme in the province as well as two clinical specialists, one in obstetrics and gynaecology and the other in paediatrics. Consultation with the team was a deliberative process during which baseline coverage levels (Table 1) as well as the interventions, their meaning and application in the provincial context was discussed and explored.

Using 2011 as baseline, we used a provincial maternal mortality rate of 187 deaths per 100,000 live births [27], a neonatal mortality rate of $13.6 / 1,000$ [29] and an under5 mortality rate of 37.08/1,000 (estimated from vital statistics data, adjusted for underreporting using national level methods) (Additional file 1: Worksheet 2) [14]. Baseline stillbirth rate was 23/1 000 live births [28]. The causes of maternal mortality [27] and neonatal and child mortality [14] were adapted from their source estimates to fit the causal categories in LiST, and adjustments were validated by the clinical provincial team by comparison to nationally reported estimates [3] and provincial estimates where these were available [12, 14] (Fig. 1).

\section{Projection and analysis}

The provincial team was also asked to project the level of coverage for each intervention that they estimated KZN would reach by 2019, if concerted effort were realistically applied and considering existing policy changes, resource inputs and observed local impacts of existing services (Table 1), i.e., the level of coverage attained by realistically scaling up essential interventions. In this paper, this level of coverage is referred to as 'achievable coverage'.

The LiST was used to analyze the number of deaths of mothers, newborns and children and stillbirths that could be averted by scaling up all interventions in the model from their baseline coverage estimates to:

- A full coverage scenario (defined as all interventions increased to $95 \%$ coverage) and

- An achievable coverage scenario (estimated achievable coverage varies per intervention)

The "full coverage" scenario aimed to show what would be possible in terms of reducing the numbers of deaths, if a universal coverage was achieved for all interventions, whereas the "achievable scenario" was considered to be what could be realistically achieved with the prevailing conditions in the province. The achievable scenario was also used for the subsequent costing exercise to inform provincial planning.

Family planning also contributes significantly in reducing the numbers of overall deaths of mothers, infants and children, and reducing the number of stillbirths. Averting unwanted pregnancies through improved family planning and birth spacing can potentially have a substantial impact on reductions in maternal and perinatal deaths [30]. Thus, in addition to the two base scenarios, two analyses were completed for contraceptive use prevalence (using the FamPlan Module of Spectrum):

- Contraceptive use increases by 0.5 percentage points per annum from baseline

- Contraceptive use increases by one percentage point per annum from baseline

The FamPlan method mix was determined at baseline for 2014 using information from the provincial DHIS, and main changes to the mix were an increase in the uptake of the newly introduced etonorgestrel implant, with ongoing decrease of the percentage use of intrauterine devices and injectable options - a trend which was already evident from the contraceptive utilization data (Additional file 1: Worksheet 3).

The effect of scaling up the maternal and child intervention coverage was modelled to estimate the deaths averted, overall and by each intervention.

\section{Costing methodology}

Intervention costs were calculated from a provider perspective, using the costing module within the LiST. The module uses an ingredients approach to costing, based on four main components: personnel and labour; drugs and supplies; other recurrent costs and capital costs. The first year of costing was 2014 .

Staff remuneration was based on current salary structures for healthcare workers in South Africa, as published, and adjusted for annual increases, at $5.6 \%$ per annum [31]. For unit costs of medicines and supplies, the default values in LiST were used. These unit costs are based on international prices from UNICEF and the Management Sciences for Health International Drug Price Indicator Guide 2011 [32]. Unit costs in Spectrum for medicines and supplies were generally comparable to the South African prices of drugs and supplies on various national tenders in most instances, although changes were made specifically to the costs for family planning commodities, since the costs of the sub-dermal implant had decreased substantially [33].

Recurrent costs related to hospitalization and outpatient visits were not included. Recurrent costs include personnel training, gasoline, building rent, office supplies and promotional activities. These were outside of the scope of the analysis. Capital costs such as infrastructure expenditure were also excluded from the analysis. Thus the costing reflects purely the scaling up of the delivery of each intervention in terms of costs of staff time and costs of medicines and supplies.

To judge the relative additional number of lives saved against the relative additional costs incurred to scale up 
Table 1 Baseline intervention coverage based and achievable levels for LiST interventions as adapted and modified by provincial experts (July 2014)

\begin{tabular}{|c|c|c|}
\hline \multirow[t]{2}{*}{ Intervention } & Baseline reviewed by experts (KZN) & Achievable scale up by 2019 estimate \\
\hline & \multicolumn{2}{|l|}{$2014(\%)$} \\
\hline \multicolumn{3}{|l|}{ Preconceptual options } \\
\hline Folic acid supplementation/fortification & 90 & 93 \\
\hline Safe abortion services & 20 & 60 \\
\hline Post abortion case management & 0 & 20 \\
\hline Ectopic pregnancy case management & 0 & 0 \\
\hline \multicolumn{3}{|l|}{ Pregnancy interventions } \\
\hline Antenatal care & 53.9 & 65 \\
\hline$\Pi$ - Tetanus toxoid vaccination & 60 & 90 \\
\hline Syphilis detection and treatment & 50 & 85 \\
\hline \multicolumn{3}{|l|}{ Nutritional } \\
\hline Calcium supplementation & 50 & 80 \\
\hline \multicolumn{3}{|c|}{ Micronutrient supplementation (multiple micronutrients + iron folate) } \\
\hline Iron folate supplementation & 80 & 90 \\
\hline Multiple micronutrient supplementation & 60 & 75 \\
\hline Balanced energy supplementation & 2 & 20 \\
\hline \multicolumn{3}{|l|}{ Case management } \\
\hline Hypertensive disease case management & 60 & 80 \\
\hline Diabetes case management & 10 & 20 \\
\hline MgSO4 - Management of pre-eclampsia & 70 & 90 \\
\hline FGR - Fetal growth restriction detection and management & 10 & 25 \\
\hline \multicolumn{3}{|l|}{ Child birth } \\
\hline Skilled birth attendance (SBA) & 84.5 & 90 \\
\hline Facility delivery (clinic and hospital) & 84.5 & 90 \\
\hline \multicolumn{3}{|l|}{ Level of delivery } \\
\hline Home deliveries & 7.2 & 5 \\
\hline Unassisted deliveries & 7.2 & 5 \\
\hline Assisted deliveries at home (SBA) & 0 & 0 \\
\hline \multicolumn{3}{|l|}{ Facility deliveries } \\
\hline Essential care & 55 & 33 \\
\hline BEmOC (Basic Emergency Obstetric Care) & 2 & 10 \\
\hline CEmOC (Comprehensive Emergency Obstetric Care) & 28 & 45 \\
\hline \multicolumn{3}{|l|}{ All deliveries } \\
\hline Clean birth practices & 80 & 90 \\
\hline Immediate assessment and stimulation & 90 & 98 \\
\hline Labor and delivery management & 93 & 98 \\
\hline Neonatal resuscitation & 40 & 95 \\
\hline Antenatal corticosteroids for preterm labor & 40 & 60 \\
\hline Antibiotics for pPRoM & 75 & 90 \\
\hline MgSO4 management of eclampsia & 90 & 95 \\
\hline AMTSL-active management of the third stage of labor & 90 & 95 \\
\hline Induction of labor for pregnancies lasting $41+$ weeks & 20 & 45 \\
\hline
\end{tabular}


Table 1 Baseline intervention coverage based and achievable levels for LiST interventions as adapted and modified by provincial experts (July 2014) (Continued)

\begin{tabular}{l} 
Intervention \\
\hline Promotion of breastfeeding \\
Preventive options \\
Postnatal care \\
Preventive postnatal care \\
Thermal care \\
Clean postnatal practices \\
Chlorhexidine \\
Feeding and supplements \\
Complementary feeding-education only \\
Complementary feeding-supplementation and education \\
Vitamin A supplementation \\
Zinc supplementation \\
WASH \\
Improved water source \\
Water connection in the home \\
Improved sanitation - Utilization of latrines or toilets \\
Hand washing with soap \\
Hygienic disposal of children's stools \\
Vaccines \\
Potavirus \\
Measles \\
Hib
\end{tabular}

Baseline reviewed by experts (KZN) Achievable scale up by 2019 estimate $2014(\%)$

$80 \quad 90$

Curative options

Neonatal

Maternal Sepsis case management

KMC - Kangaroo mother care

Case management of severe neonatal infection

Oral antibiotics

Injectable antibiotics

Full supportive care

Diarrhoea

ORS - oral rehydration solution

Antibiotics - for treatment of dysentery

Zinc - for treatment of diarrhoea

Other infectious diseases

Oral antibiotics: case management of pneumonia in children 
Table 1 Baseline intervention coverage based and achievable levels for LiST interventions as adapted and modified by provincial experts (July 2014) (Continued)

\begin{tabular}{lll}
\hline Intervention & Baseline reviewed by experts (KZN) & Achievable scale up by 2019 estimate \\
& $2014(\%)$ & 90 \\
\hline Vitamin A - for treatment of measles & 75 & 90 \\
Antimalarials - Artemesin compounds for malaria & 0 & 50 \\
Therapeutic feeding - for severe wasting & 0 & 10 \\
Treatment for moderate acute malnutrition & 0 & 50 \\
\hline
\end{tabular}

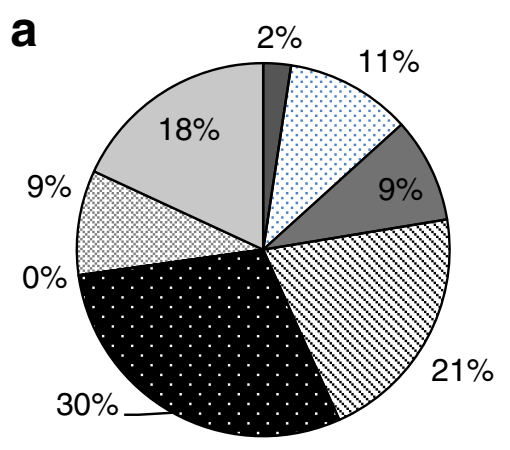

b

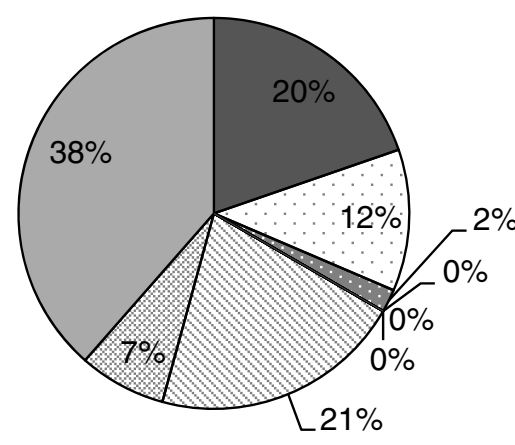

c

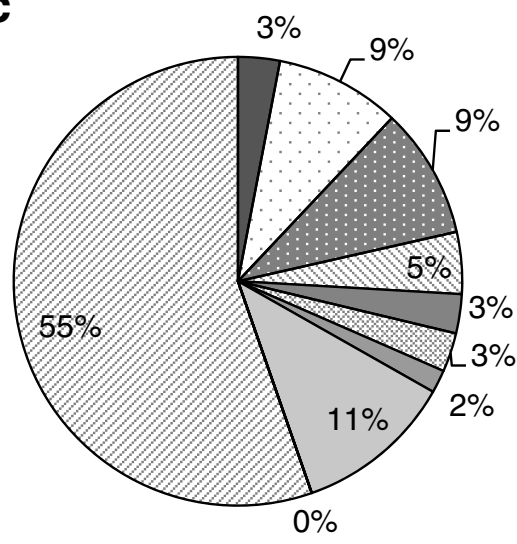

口Diarrhoea

๑Sepsis

口Pneumonia

\$Asphyxia

- Prematurity

口Tetanus

๑Congenitaanomalies

口Other

\section{口Diarrhoea}

口Pneumonia

aneningitis

$\square$ Measles

口Malaria

$\square$ Pertussis

๑AIDS

@injury

口Other

$\square$ Antepartum haemorrhage

$\square$ Postpartum haemorrhage

口Hypertensive diseases of pregnancy

๑Sepsis

$\square$ Abortion

هObstructed labour

$\square$ Ectopic pregnancy

口Other Direct (embolic, sudden

collapse, anaesthetic complication)

口Malaria

๑Other Indirect (Infectious diseases including HIV and Tuberculosis)

Fig. 1 Proximate Causes of a newborn deaths, $\mathbf{b}$ deaths in children 1-59 months of age and c maternal deaths in KwaZulu-Natal in 2011. Source: Adapted from Stats SA and Vital Registration details of newborn deaths in 2010 and 2011 and the National Confidential Enquiries on Maternal Deaths Interim Report 2011 and 2012 
interventions, a ratio cost per life year saved was determined. This was done by multiplying the lives saved by the expected life expectancy for each life saved. The average provincial life expectancy in 2014 of 54.4 years [7] was used for child and neonatal deaths and stillbirths prevented. For maternal lives saved, we used the Reproductive-Aged Life Expectancy - RALE [34], estimated to be 27 years, or half of the average life expectancy at birth.

\section{Results}

Reduction in child newborn and maternal mortality and stillbirths by 2019

\section{Full coverage (95\%)}

The model estimated that if all interventions were to be scaled up to full coverage (95\%) from baseline by 2019, maternal mortality could be reduced by $50 \%$ to $74 / 100,000$. Neonatal and under-5 mortality both reduce by $46 \%$ to $5.6 / 1,000$ and $17.8 / 1,000$ respectively.

At full coverage by 2019, 5 interventions would account for $81 \%$ of additional maternal lives saved, 12 interventions would account for $70 \%$ of additional child lives saved, and 3 interventions for $83 \%$ of stillbirths prevented (Table 2). Labour and delivery management is an intervention highly ranked in saving both maternal and child lives, and preventing stillbirths. Promotion of breastfeeding and handwashing with soap, two community based interventions, could have a significant impact on saving child lives, accounting for nearly $20 \%$ of child lives saved over 5 years.

\section{Achievable coverage}

The achievable coverage scenario demonstrated a reduction in maternal mortality of $26 \%$ to $110 / 100,000$ and $28 \%$ for neonatal and under-5 mortality to $7.5 / 1,000$ and $23.5 / 1,000$.

This mortality rate decrease translates into the potential to save an additional 297 maternal, 2,300 neonatal and 4,800 one-month to five-year old lives cumulatively by 2019 as coverage levels are improved (Table 3).

In the achievable coverage scenario, 5 interventions account for $74 \%$ of additional maternal lives saved, 12 interventions account for $77 \%$ of child lives saved and 2 interventions account for $75 \%$ of stillbirths prevented. Labour and delivery management again features as an intervention common to saving lives in all three areas. In total, these 17 interventions could potentially save 5,388 additional child lives, 218 maternal lives and prevent an additional 1,543 stillbirths from 2015 to 2019 (Table 3). For saving maternal lives, early detection and treatment of HIV, labour and delivery management and TB treatment in pregnant women are the most important, given the high burden of maternal deaths from HIV and $\mathrm{TB}$ in the province and the relatively high mortality from hemorrhage. For children, coverage of several preventative measures was quite high at baseline, with the result that curative measures such as provision of oral rehydration solution and full supportive care for sepsis and pneumonia in neonates save a large number of additional lives. Promotion of breastfeeding can also have a significant impact on saving lives, if increased promotion is associated with increased exclusive breastfeeding behavior. Labour and delivery management remains the most important intervention in the prevention of stillbirths.

\section{Addition of increasing contraceptive prevalence}

With the addition of improving contraceptive prevalence in parallel with achievable scale up of maternal and child interventions, the potential number of lives saved increases even further. When contraceptive prevalence increases by 0.5 percentage points per annum from 2015 to 2019, a further 69 maternal deaths, 1,452 child deaths and 1,135 stillbirths could be prevented (Additional file 2: Worksheet 4). If contraceptive prevalence increases by 1 percentage points per annum from 2015 to 2019, a further 137 maternal deaths, 3,168 child deaths and 2014 stillbirths could be prevented (Additional file 2: Worksheet 5).

\section{Costs for achievable coverage scenario}

The baseline cost in 2014 for the total suite of LiST interventions for which costs were estimated was US\$123 million (about US\$11.62 per capita and the 2014 provincial population estimate of 10.69 million [7]).

Table 4 summarizes the costs expected over 5 years if the full list of interventions is scaled to achievable coverage. With no increases in contraceptive use, the total cost of these interventions would be an additional US $\$ 141$ million over the five-year period, or approximately US $\$ 2.65$ per capita per annum. Where contraceptive use is assumed to increase, the additional costs of contraceptive services increase from US\$15.3 million with no contraceptive scale up, to US\$20.1 million where contraceptive use prevalence increases by one percentage point per year. Despite this increase, overall costs for the scale up of services decreases from US $\$ 140.6$ million to US $\$ 102.8$ million. Thus improved contraceptive use is cost saving, by US\$37.8 million, where all else remains equal.

Scaling up only the priority list of seventeen interventions would cost US\$91 million over five years, or US\$1.72 per capita per year (Table 5). Thus $64 \%$ of potential expenditure can achieve about $75 \%$ of the additional lives saved.

When the contraceptive prevalence rate increases by 0.5 percentage points per annum, the overall cost increase to scale up the 17 priority interventions reduced, and an additional US\$79 million would be required over the five years for these priority interventions (US\$1.49 per capita per annum) (Table 5). Where contraceptive prevalence 
Table 2 Ranked additional lives saved per LiST intervention by maternal and child lives saved and stillbirths prevented 2019 if fully scaled up (95 \%) from baseline

\begin{tabular}{|c|c|c|c|c|c|c|c|c|c|}
\hline Rank & Interventions saving maternal lives & $\begin{array}{l}\text { Total lives } \\
\text { saved }\end{array}$ & $\begin{array}{l}\text { \% of lives } \\
\text { saved }\end{array}$ & $\begin{array}{l}\text { Interventions saving child lives } \\
(0-60 \text { months) }\end{array}$ & $\begin{array}{l}\text { Total lives } \\
\text { saved }\end{array}$ & $\begin{array}{l}\text { \% of lives } \\
\text { saved }\end{array}$ & Interventions preventing stillbirths & $\begin{array}{l}\text { Total lives } \\
\text { saved }\end{array}$ & $\begin{array}{l}\text { \% of lives } \\
\text { saved }\end{array}$ \\
\hline 1 & Labour and delivery management $^{a}$ & 146 & 25.4 & Promotion of breastfeeding & 1332 & 10.9 & Labour and delivery management $^{\mathrm{a}}$ & 2132 & 47.1 \\
\hline 2 & $\begin{array}{l}\text { Early detection and treatment of HIV } \\
\text { (pregnant women) }\end{array}$ & 137 & 23.8 & Hand washing with soap & 909 & 7.4 & Syphilis detection and treatment & 962 & 21.3 \\
\hline 3 & TB treatment in pregnant women & 83 & 14.4 & Labour and delivery management $\mathrm{t}^{\mathrm{a}}$ & 895 & 7.3 & $\begin{array}{l}\text { Foetal growth restriction detection } \\
\text { and management }\end{array}$ & 577 & 12.8 \\
\hline 4 & Safe abortion services & 58 & 10.1 & Water connection in the home & 867 & 7.1 & All other interventions (5) & 785 & 17 \\
\hline 5 & Inter-facility transport & 26 & 4.5 & Antiretroviral Therapy (ART) & 721 & 5.9 & & & \\
\hline 6 & All other interventions (9) & 110 & 19 & $\begin{array}{l}\text { Antenatal corticosteroids for preterm } \\
\text { labour }\end{array}$ & 636 & 5.2 & & & \\
\hline 7 & & & & Full supportive care for sepsis/pneumonia & 609 & 5.0 & & & \\
\hline 8 & & & & Pneumococcal Vaccine & 598 & 4.9 & & & \\
\hline 9 & & & & Therapeutic feeding - for severe wasting & 552 & 4.5 & & & \\
\hline 10 & & & & ORS - oral rehydration solution & 540 & 4.4 & & & \\
\hline 11 & & & & $\begin{array}{l}\text { PMTCT - Prevention of mother to child } \\
\text { transmission of HIV }\end{array}$ & 461 & 3.8 & & & \\
\hline 12 & & & & $\begin{array}{l}\text { Improved sanitation - Utilization of latrines } \\
\text { or toilets }\end{array}$ & 458 & 3.7 & & & \\
\hline \multirow[t]{3}{*}{13} & & & & All other interventions (23) & 3662 & 30 & & & \\
\hline & $\begin{array}{l}\text { Maternal lives saved by top five } \\
\text { interventions 2015-2019 }\end{array}$ & 450 & 81 & $\begin{array}{l}\text { Child lives saved by top } 12 \text { interventions } \\
\text { 2015-2019 }\end{array}$ & 8578 & 70 & $\begin{array}{l}\text { Stillbirths prevented by top } 3 \\
\text { interventions 2015-2019 }\end{array}$ & 3671 & 83 \\
\hline & Total maternal lives saved 2015-2019 & 560 & 100 & Total child Lives saved 2015-2019 & 12240 & 100 & $\begin{array}{l}\text { Total stillbirths prevented } \\
\text { 2015-2019 }\end{array}$ & 4456 & 100 \\
\hline
\end{tabular}


Table 3 Ranked additional lives saved per LiST intervention by maternal and child lives saved and stillbirths prevented 2019 if fully scaled up to achievable levels from baseline

\begin{tabular}{|c|c|c|c|c|c|c|c|c|c|}
\hline Rank & Interventions saving maternal lives & $\begin{array}{l}\text { Total lives } \\
\text { saved }\end{array}$ & $\begin{array}{l}\% \text { of lives } \\
\text { saved }\end{array}$ & $\begin{array}{l}\text { Interventions saving child lives } \\
\text { (0-60 months) }\end{array}$ & $\begin{array}{l}\text { Total lives } \\
\text { saved }\end{array}$ & $\begin{array}{l}\% \text { of lives } \\
\text { saved }\end{array}$ & Interventions preventing stillbirths & $\begin{array}{l}\text { Total lives } \\
\text { saved }\end{array}$ & $\begin{array}{l}\% \text { of lives } \\
\text { saved }\end{array}$ \\
\hline 1 & $\begin{array}{l}\text { Early detection and treatment of HIV } \\
\text { (pregnant women) }\end{array}$ & 69 & 23.2 & ORS - oral rehydration solution & 877 & 12.5 & Labour and delivery management ${ }^{a}$ & 779 & 37.9 \\
\hline 2 & Labour and Delivery Management $^{\mathrm{a}}$ & 53 & 17.8 & Promotion of breastfeeding & 655 & 9.3 & Syphilis detection and treatment & 764 & 37.2 \\
\hline 3 & TB treatment in pregnant women & 43 & 14.4 & $\begin{array}{l}\text { Full supportive care for sepsis and } \\
\text { pneumonia }\end{array}$ & 559 & 7.9 & All other interventions (5) & 511 & 24.9 \\
\hline 4 & Safe abortion services & 30 & 10 & Handwashing with soap & 434 & 6.1 & & & \\
\hline 5 & Maternal sepsis Case management & 23 & 7.7 & $\begin{array}{l}\text { Oral Antibiotics: Case management of } \\
\text { pneumonia in children }\end{array}$ & 421 & 6.0 & & & \\
\hline 6 & All other interventions (9) & 79 & 27 & Therapeutic feeding for severe wasting & 416 & 5.9 & & & \\
\hline 7 & & & & Pneumococcal Vaccine & 403 & 5.7 & & & \\
\hline 8 & & & & Antiretroviral Therapy (ART) & 362 & 5.1 & & & \\
\hline 9 & & & & Neonatal resuscitation & 350 & 5.0 & & & \\
\hline 10 & & & & Labour and Delivery Management ${ }^{a}$ & 317 & 4.5 & & & \\
\hline 11 & & & & Kangaroo Mother Care (KMC) & 306 & 4.3 & & & \\
\hline 12 & & & & PMTCT & 288 & 4.1 & & & \\
\hline \multirow[t]{3}{*}{13} & & & & All other interventions (23) & 1655 & 23.5 & & & \\
\hline & $\begin{array}{l}\text { Maternal lives saved by top } 5 \\
\text { interventions 2015-2019 }\end{array}$ & 218 & 74 & $\begin{array}{l}\text { Child lives saved by top } 12 \text { interventions } \\
\text { 2015-2019 }\end{array}$ & 5388 & 77 & $\begin{array}{l}\text { Stillbirths prevented by top } 3 \text { interventions } \\
2015-2019\end{array}$ & 1543 & 75 \\
\hline & Total maternal lives saved 2015-2019 & 297 & 100 & Total child Lives saved 2015-2019 & 7043 & 100 & Total stillbirths prevented 2015-2019 & 2054 & 100 \\
\hline
\end{tabular}


Table 4 Projected incremental costs from 2015 to 2019 for all interventions scaled to achievable levels within three family planning scenarios

\begin{tabular}{|c|c|c|c|c|}
\hline & & $\begin{array}{l}\text { Family planning does not } \\
\text { increase }\end{array}$ & $\begin{array}{l}\text { Family planning increases by } \\
0.5 \text { percentage points per annum }\end{array}$ & $\begin{array}{l}\text { Family planning increases by } \\
1 \text { percentage points per annum }\end{array}$ \\
\hline & & $\begin{array}{l}\text { Incremental costs over } \\
\text { five years (US\$) }\end{array}$ & $\begin{array}{l}\text { Incremental costs over five } \\
\text { years (US\$) }\end{array}$ & $\begin{array}{l}\text { Incremental costs over five } \\
\text { years (US\$) }\end{array}$ \\
\hline & Intervention costs & 125272810 & 102437129 & 82645306 \\
\hline & Family planning costs & 15290627 & 17694164 & 20113685 \\
\hline Salary increases included & Overall cost & 140563438 & 120131293 & 102758991 \\
\hline & Average Cost per annum & 28112687 & 24026258 & 20551798 \\
\hline & $\begin{array}{l}\text { Overall cost per capita per } \\
\text { annum }^{\mathrm{a}}\end{array}$ & 2.65 & 2.27 & 1.94 \\
\hline
\end{tabular}

${ }^{a}$ Assuming population of 10.6 million people

rate increased by 1 percentage point per annum, this cost saving effect was more pronounced, resulting in total incremental costs of US\$67 million (US\$1.26 per capita per annum). Thus in the prioritized interventions, improving contraceptive prevalence could save US $\$ 24$ million over five years.

The inclusion of improved contraceptive coverage brings the overall incremental costs down for the provision of the same package, despite increasing costs for contraception methods. The resultant reduced pregnancies and births results in lower demand for other services in the form of the LiST interventions, and hence reduced costs in other areas.

\section{Costs to lives saved ratios}

Achieving value for money requires that outcomes be related to the costs to achieve them. Cost per life year gained ratios can assist to indicate the relative impacts of costs and impacts on lives saved The costs per life year saved for each intervention are given in Additional file 2: Worksheets 4 and 5 . The ratios demonstrate the relationship between life years saved and the costs required to achieve these life years saved, which can also be used to prioritize interventions.
Scaling up neonatal resuscitation by $55 \%$ for example, could save 305 neonatal lives, and has a cost per life saved ratio of US\$2 per life year saved. The budget impact over five years was estimated at between US $\$ 29,000$ and US $\$ 33,000$, depending on the degree of increase in contraceptive usage. Scaling up labour and delivery management by $5 \%$ could save about 1,000 additional lives and has a cost per life year saved of US $\$ 420$ per life year saved where contraceptive prevalence increases by 0.5 percentage points per year, and US\$296 where contraceptive prevalence increases by 1 percentage point per year.

Having impact and costing information as well as a ratio between the two could enable to province to prioritize the most effective interventions, those with the least budget impact, or those with the most favourable ratio between the two.

\section{Discussion}

This analysis represents the first attempt to undertake a prioritization and costing analysis for maternal and child health interventions at a provincial level in South Africa, taking into account local diseases burden, demographics and intervention coverage in the province, to inform the strategic planning process and ensure it is relevant to

Table 5 Projected incremental costs from 2015 to 2019 for top 17 interventions scaled to achievable levels within three family planning scenarios

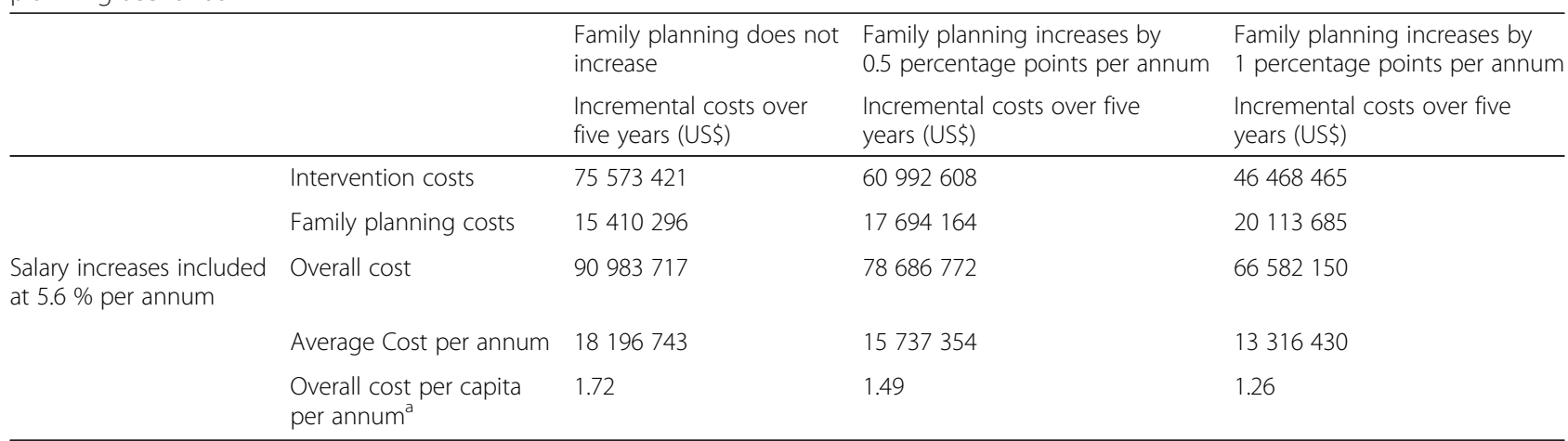

\footnotetext{
${ }^{a}$ Assuming population of 10.6 million people
} 
the specific needs of the KZN population. LiST has previously been described as a catalyst in programme planning in other African countries where used for incountry analyses [35]. Costing analysis is a more recent addition to the LiST, and has enabled the identification of intervention priorities in South Africa and costs at a national level, and the costs and impacts of scaling up targeted interventions on particular outcomes [36, 37]. All of these analyses have shown that a small number of interventions from the large collective of potential interventions can have substantial impacts on mortality in the different settings. The South African MDG analysis highlights that a "one size fits all" set of priorities, as the national-level analysis developed, does not address local targets for the implementation of key interventions [3]. We have shown that by prioritizing seventeen interventions plus family planning, several thousand additional neonatal, child and maternal lives could be saved and stillbirths prevented over the next five years in KZN province.

Family planning is the most significantly impactful single intervention for saving the lives of mothers and babies [38]. Family planning not only prevents additional deaths, but also reduces the overall additional costs of delivery of the priority interventions. Because increased contraceptive prevalence means fewer pregnancies and births which reduces the demand for other maternal and child health interventions in future. This could not only help free up much required resources to be used in other developmental programmes, but also potentially assist to ensure that existing programmes in interventions can be delivered at a higher level of quality, given that delivery and treatment facilities will have to deal with fewer births, complications of pregnancy and sick children. Unfortunately, the model itself is unable to capture these effects directly.

Of all the LiST interventions, labour and delivery management has the most significant impact overall through its effect on stillbirth outcomes, maternal and neonatal deaths. The impact of labour and delivery management is determined by a combination of factors including the proportion of deliveries and the level of obstetric care offered in facilities (comprehensive emergency obstetric care, basic emergency obstetric care, or essential care). Thus the impact of labour and delivery management reflects both the increase in facility births and level of care provided. Promotion of breastfeeding can potentially also make a significant contribution to saving child lives in the province. Other important interventions are largely curative, such as provision of oral rehydration solution to children with diarrhea, and full supportive care for sepsis and pneumonia in neonates.

There are additional cost considerations related to scaling up coverage for any of the interventions and we recommend that the province prioritize in order of effectiveness and cost effectiveness of the various potential interventions for saving maternal and child lives and preventing stillbirths.

In line with the South African National Treasury's framework for strategic plans, this analysis shows the potential for health impacts of delivered programmes, as well as estimating the additional costs required to achieve these improved health outcomes to ensure value for money.

The explicit derivation of the outcomes, the costs required to achieve them and the ratios between outcomes achieved relative to costs, can empower provincial authorities to make decisions as to what interventions to prioritize, on the basis of effectiveness, budget impact or costs in relation to outcomes.

\section{Study limitations}

While this analysis has attempted to show outcomes and costs for the next five years, there are some challenges which will need to be addressed. This analysis represents modelled outcomes of what could be achievable if coverage can be increased for key interventions. However, translation from theory into practice can be difficult, and actual real world outputs and impacts on mortality will depend on the ability of the existing system to support the increased coverage of these interventions, and to overcome implementation barriers. On the basis of this analysis, the province has implemented an auditing program for the use of partograms to monitor labour, to improve labour and delivery management. In addition a pilot project to target family planning services in one of the more deprived districts in the province has begun. The impacts and outcomes of these programmes will require monitoring and evaluation to measure their impact.

The estimations of "achievable" coverage goals for 2019 remain fairly arbitrary as it is difficult to estimate what the province might actually be capable of in the next five years if the resources are correctly deployed. Relatively high levels of coverage for interventions such as prevention of mother to child transmission (PMTCT) of HIV in the province have however shown that high coverage levels for intervention can be attained with concerted effort.

In addition, the coverage levels inputted into the model cannot take into account the quality aspects of the delivery of the interventions. So, for example, where vaccination coverage has been estimated at $72 \%$, it is assumed that vaccinations which are received are administered correctly and have had cold chain conditions maintained. It is also assumes the training of birth attendants and other health care workers is adequate and that a critical mass of such individuals is present in each facility, whereas a survey in South Africa has shown that there are frequently insufficient personnel at some delivery sites [39]. 
Cost calculations show the minimum of what would be required and do not include the costs of infrastructure development, training of staff where necessary and additional promotional activities. Taking these into account would increase the total costs. The estimates provided can however still guide provincial health department budgetary considerations with regard to providing a maternal and newborn health package.

The heterogeneity in mortality rates and intervention coverage across the province is also not adequately captured by the provincial-level analysis. KwaZulu-Natal has 11 health districts which report varying coverage levels for key interventions such as childhood vaccines, PMTCT, as well as access to utilities such as piped water. In order to completely localize the estimates from the LiST tool, an analysis would have to be completed at a district level.

\section{Conclusion}

This modelling has attempted to identify and cost priority intervention areas for impact on maternal and child mortality over the next five years in KwaZulu-Natal Province, South Africa. We show that focusing on seventeen essential interventions and improvement of contraceptive use prevalence could result in an MMR of 129 per 100,000 live births and an NMR of 9 per 1,000 live births, and under-5 deaths of 27 per 1,000 live births. The additional cost per capita per annum for this is US\$1.72. Improvement of family planning coverage saves both costs and lives. If family planning coverage and contraceptive prevalence also increase simultaneously, 2600 to 5300 additional deaths can be avoided as well as achieving significant cost savings for the system as a whole.

The priority interventions identified in this analysis are specific to the province and reflect its burden of disease and potential for improvement in coverage additional analyses would be necessary to determine priorities for other provinces in the country.

In the post-2015 agenda, investing in family planning and decisions to prioritize either most effective or most cost effective identified interventions will be key to achieving the KwaZulu-Natal province's outcome and financial goals.

\section{Additional files}

Additional file 1: Sheet 1. Interventions added to List. Additional interventions not included in the LiST Tool, with descriptions, effect sizes and affected fractions. Sheet 2. Adjusted Mortality. Deaths reported to Statistics South Africa, adjusted for under-reporting to estimate actual mortality rates for neonatal and under-five mortality. Sheet $\mathbf{3}$. Changes in contraceptive mix. Changes in the assumption of proportion of different contraceptive choices used by the population over time (2015 to 2019). (XLSX $15 \mathrm{~kb}$ )

Additional file 2: Sheet 4. Summary of impacts of scaling up LiST interventions to achievable levels from baseline by 2019 and a 0.5 percentage point per annum increase in contraceptive prevalence. Summary of lives saved, life years gained, costs over five years and cost to life years gained ratios for all interventions where contraceptive prevalence increases by 0.5 percentage points per annum. Sheet $\mathbf{5}$. Summary of impacts of scaling up LiST interventions to achievable levels from baseline by 2019 and a one percentage point per annum increase in contraceptive prevalence. Summary of lives saved, life years gained, costs over five years and cost to life years gained ratios for all interventions where contraceptive prevalence increases by one percentage point per annum. (XLSX $27 \mathrm{~kb})$

\section{Competing interests}

The authors declare that they have no competing interests.

\section{Authors' contributions}

All authors are responsible for the study concept and design. NMc, NM and VM provided provincial level data and estimates and assisted in the interpretation of the results. SM performed the analysis and drafted the manuscript. LC, KH, LK, NMc and AT reviewed and provided critical review of the manuscript. All authors read and approved the final manuscript.

\section{Acknowledgements}

We wish to acknowledge the United Nations Population Fund for their organizational support of this project, in particular Leonard Kamugisha, Linda Naidoo and Lebogang Schultz.

We also wish to thank Valerie Makatini and Zipho Mngomezulu of the KwaZulu -Natal Provincial Department of Health for the provision of contraceptives data from the provincial database.

\section{Funding}

UNFPA - United Nations Population Fund, South Africa Office and PRICELESS grant from the Medical Research Council - South Africa \# D1305910 -01.

\section{Author details}

${ }^{1}$ Priority Cost-Effective Lessons for System Strengthening South Africa (PRICELESS SA), Medical Research Council/Wits Rural Public Health and Health Transitions Research Unit (Agincourt), Wits School of Public Health, Faculty of Health Sciences, University of the Witwatersrand, Wits Education Campus, 27 St Andrews Road, Parktown 2193, Johannesburg, South Africa. ${ }^{2}$ Department of Health, Province of KwaZulu-Natal, Pietermaritzburg, South Africa. ${ }^{3}$ Department of Obstetrics and Gynaecology, Nelson R Mandela School of Medicine, University of KwaZulu-Natal, Durban, South Africa. ${ }^{4}$ Department of Paediatrics and Child Health, Nelson R Mandela School of Medicine, University of KwaZulu-Natal, Durban, South Africa. ${ }^{5}$ United Nations Population Fund (UNFPA), Pretoria, South Africa.

Received: 29 July 2015 Accepted: 22 December 2015

Published online: 19 January 2016

\section{References}

1. Kerber KJ, Lawn JE, Johnson LF, Mahy M, Dorrington RE, Phillips H, et al. South African child deaths 1990-2011: have HIV services reversed the trend enough to meet Millennium Development Goal 4? AIDS. 2013;27(16):2637-48.

2. Dorrington $R$, Bradshaw D, Laubscher R, Nannan N. Rapid mortality surveillance report 2013. Cape Town: South African Medical Research Council; 2014

3. Chola L, Pillay Y, Barron P, Tugendhaft A, Kerber K, Hofman K. Cost and impact of scaling up interventions to save lives of mothers and children: taking South Africa closer to MDGs 4 and 5. Glob Health Action. 2015;8:27265. doi: 10.3402/ gha.v8.27265. eCollection 2015.

4. National Health Act 61 of 2003. South African National Department of Health. 2003.

5. Shisana O, Rehle T, Simbayi L, Zuma K, Jooste S, Zungu N, et al. South African National HIV Prevalence, Incidence and Behavioural Survey, 2012. Pretoria: Human Sciences Research Council; 2014.

6. South African National Treasury. Framework for Managing Programme Performance Information. Pretoria: South African National Treasury; 2007.

7. Mid-Year Population estimates 2014. Statistical Release P0302. Pretoria: Statistics South Africa; 2014. 
8. Day C, Gray A. Health and Related Indicators. In: Padarath A, English R, editors. South African Health Review 2013/2014. Durban: Health Systems Trust; 2014. p. 201-346

9. South African National Department of Health. The 2012 National Antenata Sentinel HIV \& Herpes Simplex Type-2 Prevalence Survey in South Africa. Pretoria: National Department of Health; 2014.

10. Loveday M, Smith J, Day C. Knowing our TB epidemic: key challenges facing the TB Programme in South Africa. In: Padarath A, English R, editors. South African Health Review 2013/2014. Durban: Health Systems Trust; 2014. p. 139-54.

11. National Committee for Confidential Enquiry into Maternal Deahts in South Africa (NCCEMD). Saving Mothers 2008-2010 - Fifth report on the Confidential Enquiries into Maternal Deaths in South Africa. Pretoria: National Department of Health; 2012.

12. National Committee on Morbidity and Mortality in Children under 5 years. Interim Report of the Committee on Morbidity and Mortality in Children under 5 years (CoMMiC): 2012. Pretoria: National Department of Health; 2013.

13. Moodley J, Pattinson RC, Fawcus S, Schoon MG, Moran N. Shweni PM, on behalf of the National Committee on Confidential Enquiries into Maternal Deaths in South A: The confidential enquiry into maternal deaths in South Africa: a case study. BJOG. 2014;121:53-60.

14. Mortality and causes of death in South Africa, 2011. Findings from death notification. Statistical release P03093. Pretoria: Statistics South Africa; 2013.

15. Spectrum Suite of Modelling Software [http://idfive.jhsph.edu/departments/ international-health/centers-and-institutes/institute-for-internationalprograms/current-projects/lives-saved-tool/spectrum-overview/]. Accessed 25 August 2014.

16. Stover J, McKinnon R, Winfrey B. Spectrum: a model platform for linking maternal and child survival interventions with AIDS, family planning and demographic projections. Int J Epidemiol. 2010;39 suppl 1:i7-10.

17. Walker N, Tam Y, Friberg I. Overview of the Lives Saved Tool (LiST). BMC Public Health. 2013;13 Suppl 3:S1

18. Fischer Walker CL, Walker N. The Lives Saved Tool (LiST) as a model for diarrhea mortality reduction. BMC Med. 2014;12:70.

19. Chola L, Michalow J, Tugendhaft A, Hofman K. Reducing diarrhoea deaths in South Africa: costs and effects of scaling up essential interventions to prevent and treat diarrhoea in under-five children. BMC Public Health. 2015;15(1):394

20. LiST: The Lives Saved Tool. An evidence-based tool for estimating intervention impact [http://www.jhsph.edu/research/centers-and-institutes/ institute-for-international-programs/current-projects/lives-saved-tool/]. Accessed 25 August 2014.

21. Newton SM, Brent AJ, Anderson S, Whittaker E, Kampmann B. Paediatric tuberculosis. Lancet Infect Dis. 2008:8(8):498-510.

22. Mathad JS, Gupta A. Tuberculosis in pregnant and postpartum women: epidemiology, management, and research gaps. Clin Infect Dis. 2012;55(11):1532-49.

23. Schoon MG. Impact of inter-facility transport on maternal mortality in the Free State Province. S Afr Med J. 2013;103(8):534-7.

24. Mortality and causes of death in South Africa, 2013. Findings from death notification. In: Statistical release P03093. Pretoria: Statistics South Africa; 2014

25. Ademuyiwa AO, Usang UE, Oluwadiya KS, Ogunlana DI, Glover-Addy H, Bode CO, et al. Pediatric trauma in sub-Saharan Africa: Challenges in overcoming the scourge. J Emergencies Trauma Shock. 2012;5(1):55-61.

26. Health Systems Trust. South African Health Review 2012/13. Durban: Health Systems Trust; 2013

27. Pattinson R, Fawcus S, Moodley J. Tenth interim report on Confidential Enquiries into Maternal Deaths in South Africa. Pretoria: National Department of Health; 2013.

28. Health Systems Trust. District Health Information System (DHIS) database [dataset]. Pretoria: Health Systems Trust; time series.

29. National Perinatal Mortality and Morbidity Committee. National Perinatal Mortality and Morbidity Committee (NaPeMMCo) Interim Report 2012 (20102011 data). Pretoria: National Department of Health; 2012.

30. Collumbien M, Gerressu M, Cleland J. Non-use and use of ineffective methods of contraception. In: Ezzati M, Lopez AD, Rogers A, Murray CJL, editors. Comparative quantification of health risks: Global and regional burden of disease attributable to selected major risk factors. Geneva: World Health Organisation; 2004. p. 1255-320.
31. South African Government Salary Scales. Appendices to DPSA Circular 2 of 2013. Pretoria: Department of Public Service Administration; 2013.

32. International Drug Price Indicator Guide. Cambridge, MA: Management Sciences for Health; 2012

33. Contract HP03-2013FP. Supply and Delivery of Family Planning Agents to the Department of Health, 1 October 2013 to 30 September 2015. Pretoria: National Department of Health; 2013.

34. Canudas-Romo V, Liu L, Zimmerman L, Ahmed S, Tsui A. Potential gains in reproductive-aged life expectancy by eliminating maternal mortality: a demographic bonus of achieving MDG 5. PLoS One. 2014;9(2):e86694.

35. Bryce J, Friberg IK, Kraushaar D, Nsona H, Afenyadu GY, Nare N, et al. LiST as a catalyst in program planning: experiences from Burkina Faso, Ghana and Malawi. Int J Epidemiol. 2010;39 Suppl 1:i40-47.

36. Michalow J, Chola L, McGee S, Tugendhaft A, Pattinson R, Kerber K, et al. Triple return on investment: the cost and impact of 13 interventions that could prevent stillbirths and save the lives of mothers and babies in South Africa. BMC Pregnancy Childbirth. 2015;15(1):1-13.

37. Chola L, McGee S, Tugendhaft A, Buchmann E, Hofman K. Scaling Up Family Planning to Reduce Maternal and Child Mortality: The Potentia Costs and Benefits of Modern Contraceptive Use in South Africa. PLoS One. 2015;10(6):e0130077

38. Cates Jr W. Family planning: the essential link to achieving all eight Millennium Development Goals. Contraception. 2010;81(6):460-1.

39. Pattinson RC. Safety versus accessibility in maternal and perinatal care. S Afr Med J. 2015;105(4):261-5

\section{Submit your next manuscript to BioMed Central and we will help you at every step:}

- We accept pre-submission inquiries

- Our selector tool helps you to find the most relevant journal

- We provide round the clock customer support

- Convenient online submission

- Thorough peer review

- Inclusion in PubMed and all major indexing services

- Maximum visibility for your research

Submit your manuscript at www.biomedcentral.com/submit 